\title{
Optimizing Aesthetic and Functional Outcomes at Donor Sites
}

\author{
Seng-Feng Jeng, MD, FACS; Ngian Chye Tan ${ }^{1}$, MBBS, FRCSEd (Gen)
}

In recent years, there has been increasing interest by reconstructive surgeons in improving the aesthetic and functional outcomes of donor sites. As the success rate of free tissue transfers has exceeded more than $95 \%$ in most microsurgical centers, more emphasis can be shifted to the donor site. However, morbidities of donor sites can occur not only in free tissue transfers, but in locoregional flaps as well. In reconstructive procedures, the main principle is to mobilize normal tissue and utilize it to reconstruct an area of defect. The donor site, of course has no pathology, but is a previously healthy area. Therefore, it is of paramount importance to not only minimize postoperative complications at recipient sites, but also pay attention to donor sites. Just as in organ transplantation where efforts are made to ensure the safety and a good outcome for a donor patient, outcomes

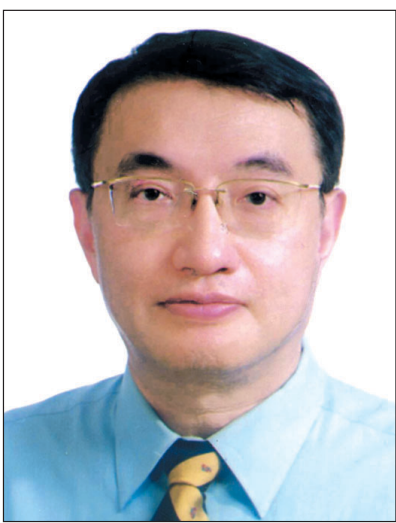

Prof. Seng-Feng Jeng should be improved and morbidity reduced at donor sites in reconstructive surgery. (Chang Gung Med J 2012;35:219-30)

Key words: reconstructive surgery, aesthetic outcome, functional outcome, complication, donor site

$\mathrm{R}^{\mathrm{s}}$ econstructive surgery has become increasingly recognized in the fields of trauma and surgical oncology. Local and free tissue transfers are regularly done all over the world to optimize the recovery of patients. Moreover, refinements in surgical technique and instrumentation have helped improve the success rate of free tissue transfers to more than $95 \%$ in most surgical centers. Having ensured a high success rate for free flaps, reconstructive surgeons are giving more emphasis to the aesthetic and functional outcomes of the recipient site in various reconstructive surgeries. Many primary and secondary procedures have been developed to improve the cosmetic and functional outcomes of recipient sites (e.g. debulking surgery, scar revision $)^{(1,2)}$
Donor site outcomes for both locoregional and free flaps in reconstructive surgery however are often neglected. The holistic care of patients is of utmost importance. Although efforts have been done to improve donor site morbidities in recent years, more can be done to ensure their aesthetic and functional outcomes. It is not uncommon for patients to have more complaints about their donor than their recipient sites. It is imperative to remember that the donor site is not the site with pathology, and thus, reconstructive surgeons should try to restore it to its original healthy state.

Strategies for optimizing donor sites outcomes when using a locoregional flap or a free flap include the following: (1) selecting flaps with good wound

From the Department of Plastic Surgery, E-Da Hospital, Kaohsiung, Taiwan; 'Department of Plastic and Reconstructive Surgery, Kaohsiung Chang Gung Memorial Hospital and Chang Gung University College of Medicine, Kaohsiung, Taiwan.

Received: Nov. 4, 2010; Accepted: Dec. 7, 2011

Correspondence to: Prof. Seng-Feng Jeng, Department of Plastic Surgery, E-Da Hospital, Kaohsiung. 1, Yida Road, Yanchao District, Kaohsiung City 824, Taiwan, R.O.C. Tel: 886-7-6150011 ext. 2977; Fax: 886-7-6155352;

E-mail: jengfamily@hotmail.com 
concealment, (2) closing donor wounds directly, and (3) improving harvesting techniques. There are many examples of these principles and strategies. The purpose of this review article is to raise awareness of the importance of reducing donor site morbidity in local and free flaps, and also share some of our experiences on how this can be done with certain flaps. In our institution, 2910 free flap transfers were done over the last 14 years. The 4 most common free flaps used were the anterolateral thigh flap, radial forearm flap, fibular osteocutaneous flap and gracilis flap (Table). We hope more innovative and novel techniques will be developed in the future to improve the outcome of donor sites in reconstructive surgery.

\section{Selecting flaps with good wound concealment}

Appropriate flap selection that allows the donor site wound to be concealed can improve the aesthetic outcome. Donor site wounds that can be hidden away in skin creases, under skin folds, by hair bearing areas or under garments should be seriously considered when choosing a flap for reconstruction. The ideal method is to choose and harvest a flap that can allow the donor site to be closed primarily with the wound well hidden, and at the same time follow Gillies" classic principle of providing "like" tissue for the recipient site. Many locoregional flaps utilize this principle, with the donor site being well concealed in a skin crease and at the same time providing a flap that has an excellent tissue and color match for the recipient site.

We will illustrate this with examples such as the melolabial flap and the submental flap. At the same time, "traditional" free flaps like the temporal parietal fascia flap and the groin flap, which are not so popular now, will be mentioned as they have the advantage of well-concealed donor sites.

Table Common Types of Free Flaps at Kaohsiung Chang Gung Memorial Hospital from 1995-2009

\begin{tabular}{lc}
\hline Type of Flap & No. \\
\hline Anterolateral thigh & 1525 \\
Radial forearm & 436 \\
Fibular osteocutaneous & 436 \\
Gracilis & 181 \\
Others & 332 \\
\hline
\end{tabular}

\section{Loco regional flaps}

The melolabial flap, otherwise commonly known as the nasolabial flap, is one good example of a local flap with a well-hidden donor site. The junction of the upper lip and lower nose with the cheek forms the melolabial sulcus, and the mound of skin lateral to this sulcus in the medial area of the cheek is called the melolabial cheek fold. This cheek fold contains abundant skin with many of the attributes required for excellent nasal and perinasal reconstruction.

This flap has a long history, but it is still one of the most reliable local flaps. Numerous techniques for lip and vermilion reconstruction have been described,$^{(3)}$ but the inferiorly based melolabial flap is one of the most useful for reconstructing defects of the upper and lower lips. The flap has a long length to width ratio, the color match and texture are good, it has an excellent blood supply from branches of the facial artery, and most of the time, the skin is free of hair.(4) Primary closure is usually possible for the donor site, and because the melolabial sulcus is a prominent facial landmark, the donor site wound is easily hidden in this area. This helps achieve excellent cosmetic results at the donor site (Fig. 1).

The submental island flap is another example of a locoregional flap with a cleverly concealed donor site. It is an axial pattern skin flap first described by Martin et al in 1993. ${ }^{(5)}$ In 1996, Falaous and Yetman demonstrated that the submental flap is reliable because it has a reliable blood supply passing through the mid-axis of the flap and it has a long vascular pedicle. The blood supply of this flap comes from the submental artery, a well-defined, consistent branch of the facial artery. ${ }^{(6,7)}$

The advantages of the submental flap include its reliability, a wide arc of rotation, excellent color and texture match, and a well-hidden donor site. In addition, this flap is relatively thin and can be harvested easily and expeditiously. The pedicle is quite long (up to $8 \mathrm{~cm}$ ), allowing the flap to reach the base of the tongue, ${ }^{(8)}$ palate, maxilla, pharynx and upper esophagus. Donor sites up to $8 \mathrm{~cm}$ wide can still be closed primarily with no obliteration of the cervicomental angle, particularly in elderly patients with ample skin laxity. Furthermore, the donor site scar is well concealed under the horizontal ramus of the mandible and is practically invisible in bearded male patients (Fig. 2). 

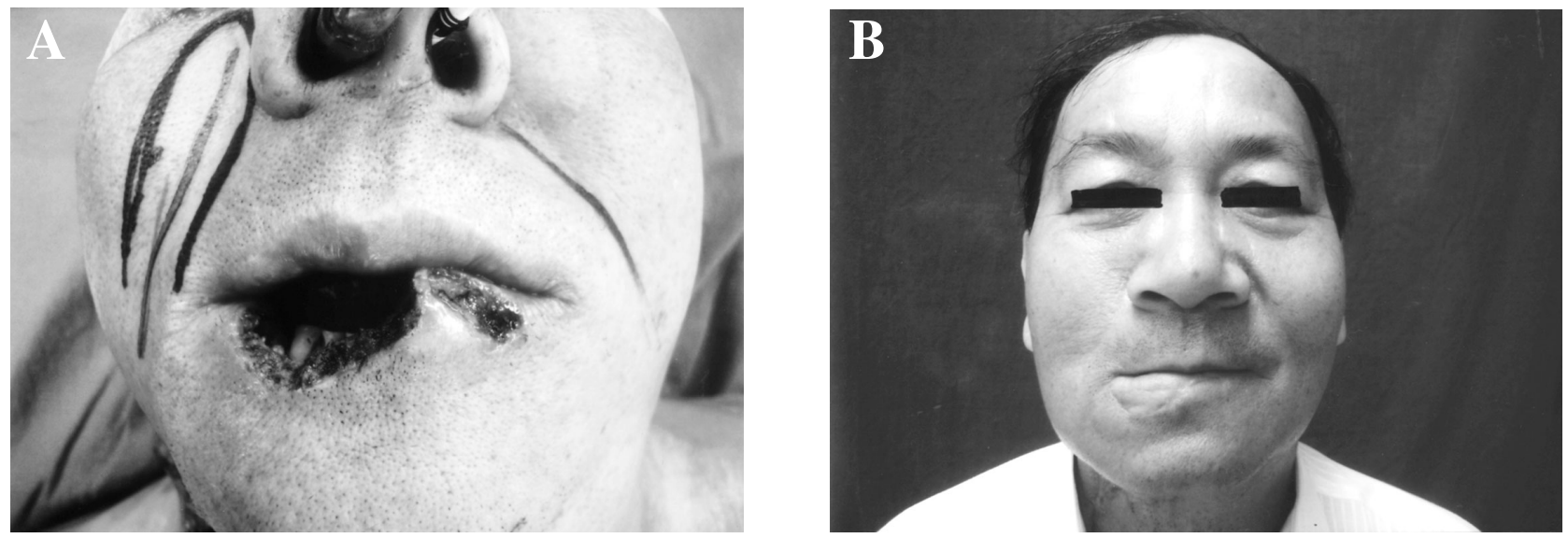

Fig. 1 (A) Patient with a right lower lip defect reconstructed with a right nasolabial flap. (B) The scar is hardly noticeable 2 years postoperatively.
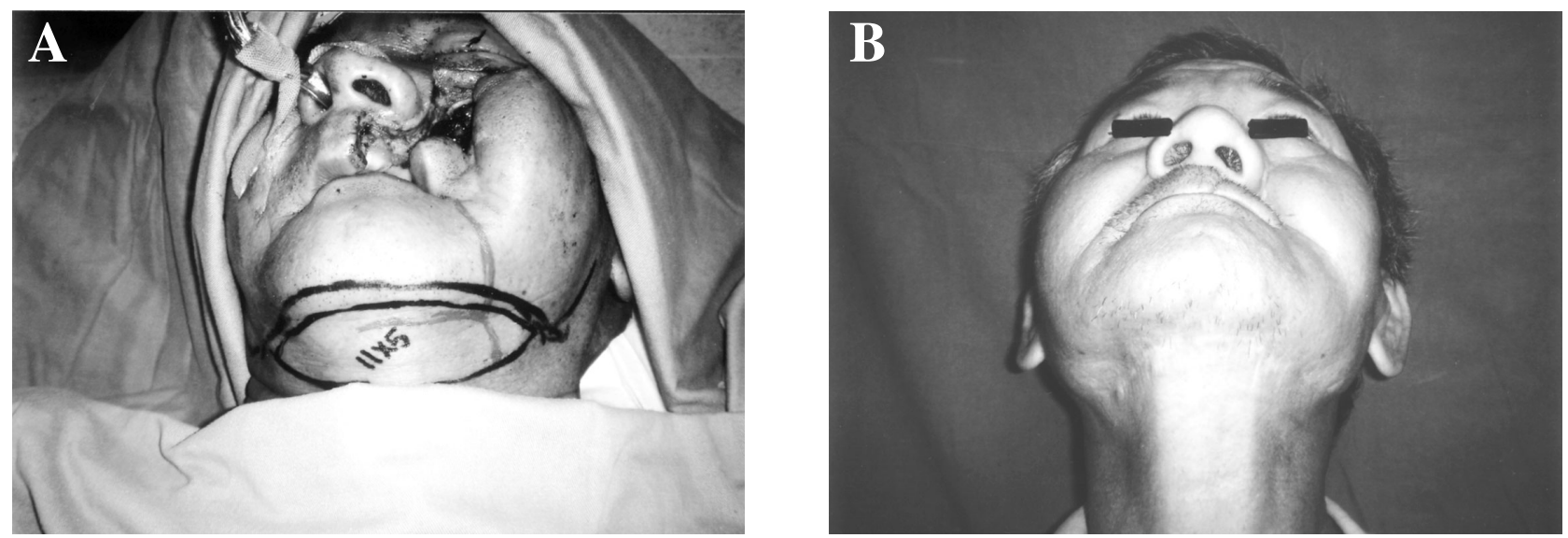

Fig. 2 (A) Patient with a left side upper palate defect. (B) Healed submental donor site wound 1 year later.

\section{Temporoparietal fascia flap}

The temporoparietal fascia is a superior extension of the superficial musculoaponeurotic system, both of which attach to the zygomatic arch. It is most commonly based on the parietal branch of the superficial temporal artery, with its accompanying vein. The temporoparietal fascia flap was first reported by Brown $^{(9)}$ and Monks ${ }^{(10)}$ separately more than a century ago to reconstruct the ear and eyelid, respectively. Since then, this flap has been used most commonly as a pedicled flap for head and neck reconstruction. However, it may also be used as a free flap when the arc of rotation is insufficient. ${ }^{(11-13)}$

The excellent features of this fascia flap are its thinness (ranges from 2 to $4 \mathrm{~mm}$ ) and pliability. It is highly vascular and exhibits a significant degree of flexibility, which allows it to be draped around grafts and into cavities. This makes it very useful in head and neck reconstruction, especially for reliable coverage of temporal bone and orbital cavities previously affected by radiotherapy. ${ }^{(14-16)}$

Perhaps one of the most significant advantages of this ultrathin flap is that it offers a well-concealed donor site in the hair-bearing scalp (Fig. 3.). ${ }^{(17)}$ A Tor Y-shaped incision made almost entirely within the patient's hairline is usually used to harvest this flap. The patient's hair, when fully grown, allows the donor site wound to be completely hidden. Nevertheless, secondary alopecia can develop after elevation of this flap. This complication can be noted up to 1 to $2 \mathrm{~cm}$ around the incision site, and is often a result of ischemic injury to previously irradiated 

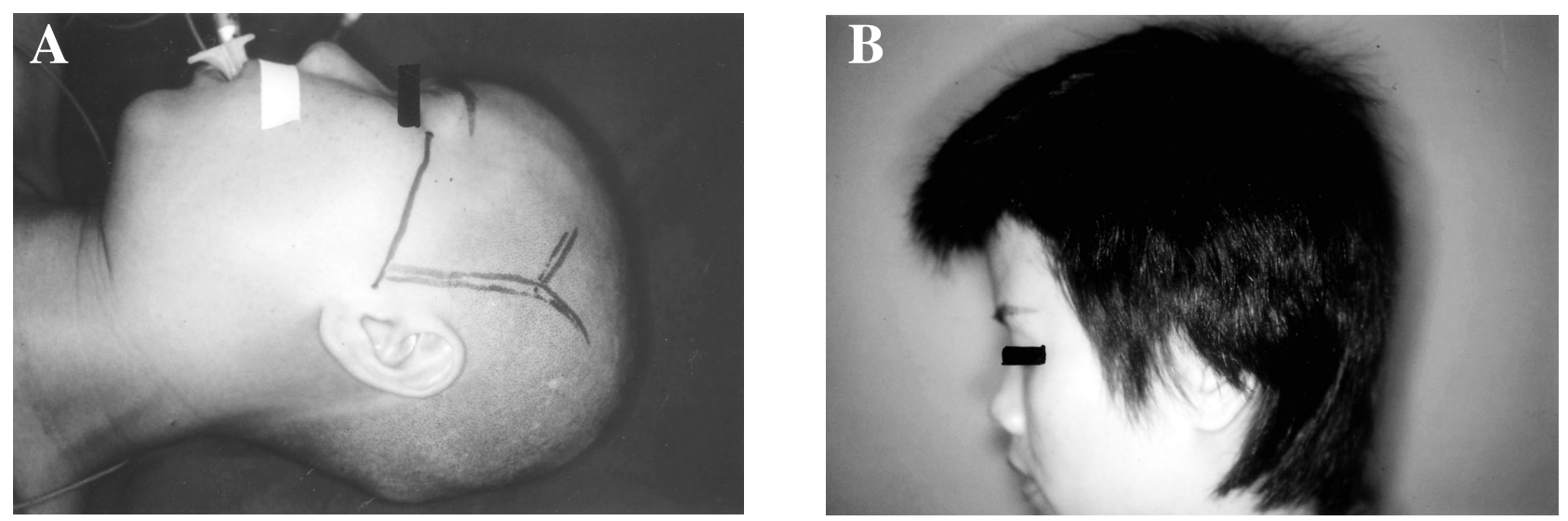

Fig. 3 (A) Design of a temporoparietal fascia flap. (B) Donor site scar is completely hidden by the patient's hair.

skin during flap elevation or direct injury to the hair follicles due to a poor plane of dissection. Therefore, it is important to be meticulous during the skin flap elevation, so as not to injure the hair follicles unnecessarily (Fig. 3).

\section{Groin flap}

McGregor and Jackson first described the groin flap in 1972, ${ }^{(18)}$ and Daniel and Taylor first reported its distant transfer in 1973. ${ }^{(19)}$ This flap can be designed as a pedicled or free flap, and its first free transfer was reported by Harii and Ohmori in 1975 to cover lower limb defects. ${ }^{(20)}$ The blood supply of the groin flap is based on the superficial circumflex iliac artery. Aydin and Nasir were able to close the donor sites of groin flaps primarily without any postoperative problems even in the largest flap size they harvested. ${ }^{(21)}$

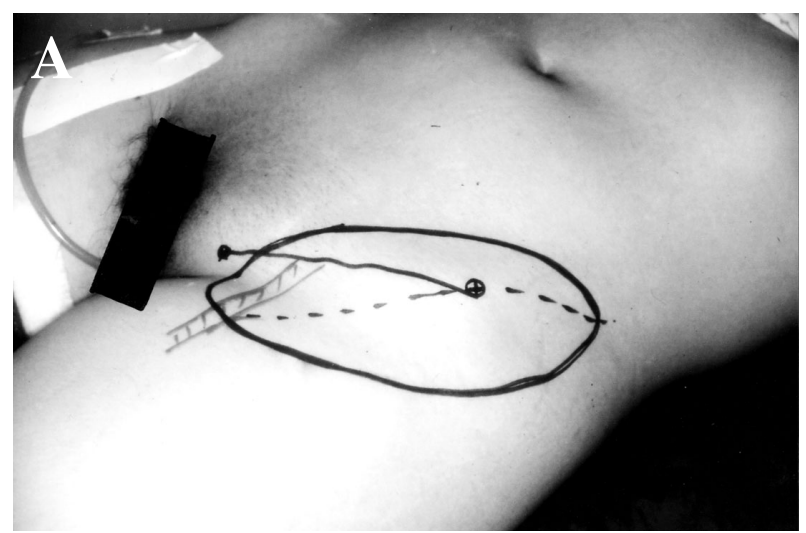

The groin flap is commonly employed in free tissue transfers for defects of the extremities. ${ }^{(22)}$ The popularity of this flap, however, has gradually decreased in recent years ${ }^{(23)}$ because of disadvantages related to its short pedicle, frequent structural variations and technically demanding harvesting. Nevertheless, the groin flap is still one of the best reconstructive options. Its numerous advantages include the prospect of a thin flap, the option of using a free or pedicled design, and most important of all, a well- concealed donor site with minimal morbidity. ${ }^{(23)}$ Primary closure of the donor site involves a linear scar that is well hidden by the groin skin crease and can be further concealed by undergarments. This flap should be considered for female and pediatric patients where donor site cosmesis is particularly important (Fig. 4).

Fig. 4 (A) Groin flap design. (B) Wound of the harvested groin flap is well concealed by undergarments. 


\section{Closing donor wounds directly}

Meticulous closure will enhance both the aesthetic and functional outcomes of donor sites in reconstructive surgery. Primary closure is ideal, but in many instances this is not possible and the donor site has to be closed with a split thickness skin graft. Good examples are the radial forearm flap and the fibula osteocutaneous flap. In more than $80 \%$ of cases, donor sites from these 2 flaps have to be closed with split thickness skin grafts, which can pose many problems for the donor site. Skin grafts often do not survive well when grafted over bare tendons and the color match is frequently compromised, resulting in poor aesthetic outomes. Moreover, many patients complain of numbness over skin grafted donor sites. In such instances, it would greatly benefit the patient if the donor site can be closed primarily or by a better alternative than skin grafting. In addition, if it can be predicted that a donor site can be closed primarily after flap harvest, the surgeon can harvest a flap that is not too large, thus precluding primary closure. We will illustrate these concepts with the radial forearm flap and anterolateral thigh fasciocutaneous flap.

\section{Radial forearm free flap}

The first free flap to be transferred on the radial artery was a segment of the superficial branch of the radial nerve, which was performed by Taylor et al in 1976. ${ }^{(24)}$ The radial forearm flap as a fasciocutaneous flap was first introduced by Yang et al in the Chinese literature in 1981. ${ }^{(25)}$ Since then, this flap has been transferred as a composite flap containing vascularised bone, ${ }^{(26)}$ vascularised tendon, ${ }^{(27)}$ the brachioradialis muscle, ${ }^{(28)}$ and vascularised nerves. ${ }^{(29)}$

The radial forearm fasciocutaneous flap is based on the radial artery and depends on the venae comitantes or the more superficial cephalic vein for venous drainage. The radial forearm flap, with its thin pliable skin and rich vascularity, has taken on a very significant role in head and neck reconstruction. Intraoral resurfacing, skull based surgery to repair the dura and pharyngoesophageal reconstruction are examples of its use.

Besides the disastrous possibility of an ischemic hand following transsection of the radial artery, the other major disadvantage of this flap is aesthetic deformity of the donor site. Conventionally, the donor site defect is closed with a split thickness skin graft. However, up to 30 percent of patients experience significant healing problems and up to 28 percent of patients complain of poor aesthetic results with a skin graft because of the presence of the flexor tendons. ${ }^{(30)}$ A variety of different techniques have been reported to modify the appearance of the skingrafted forearm defect. These include turning over and oversewing the muscle bellies of the flexor pollicis longus and flexor digitorium superficialis to bury the flexor carpi radialis tendon and improve the take of the split thickness skin graft, ${ }^{(31)}$ using longer periods of splint immobilization with hand extension to increase the contact surface of the skin graft with the musculature, ${ }^{(32)}$ and using tissue expanders. ${ }^{(3)}$ Lutz et al performed a suprafascial dissection on 95 consecutive cases when harvesting the radial forearm flap and achieved better skin graft success over the donor site. ${ }^{(34)}$ Elliot et al also used an ulnar artey- based V-Y transposition flap to primarily close a radial forearm defect. ${ }^{(35)}$ However, only small defects up to $4 \times 8 \mathrm{~cm}$ can be closed with this technique.

We have developed a new closure technique for large defects up to $8 \times 8 \mathrm{~cm}$. These defects can be closed primarily with a bilobed flap based on one or two fasciocutaneous perforators of the ulnar artey. ${ }^{(30)}$ After elevation of the flap, it is rotated and used to close the donor site defect primarily (Fig. 5). The major advantage of this novel technique is reconstruction of donor defects in a one-stage operation with no additional donor area. Thickness and color match are excellent with this method of closure. The aesthetic outcome is much more acceptable than and eliminates the problem of poor take of skin grafts on tendons. Moreover, hand motion can be allowed earlier, thus decreasing wrist joint stiffness. The only disadvantage of this technique is the lengthy post surgical scar from the multiple curved incisions.

\section{Anterolateral thigh flap}

Since its first report by Song et al in $1984,{ }^{(36)}$ the anterolateral thigh (ALT) flap has gained popularity worldwide. It can be harvested as a myocutaneous or fasciocutaneous perforator flap and can be utilized both as a free flap and as a pedicled flap. The ALT flap has become the workhorse of head and neck reconstruction and is also becoming a very popular free flap for reconstruction of the extremities. The blood supply of the ALT flap comes from the descending branch of the lateral circumflex femoral 

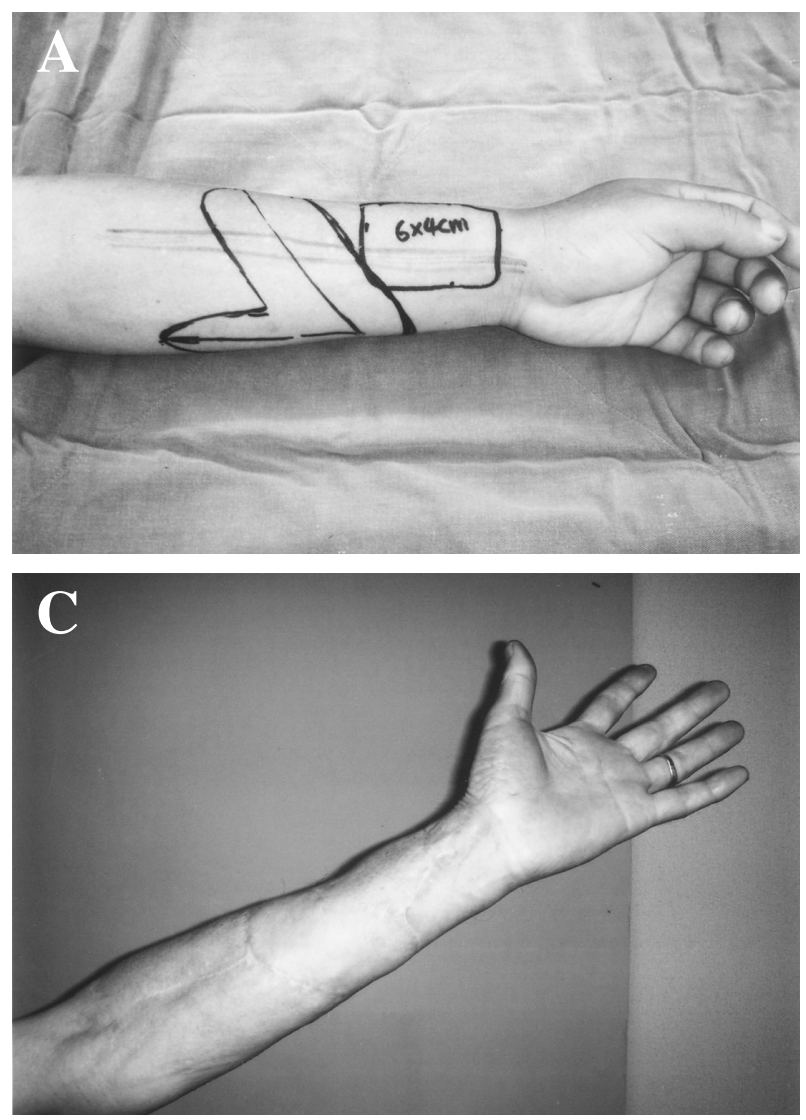
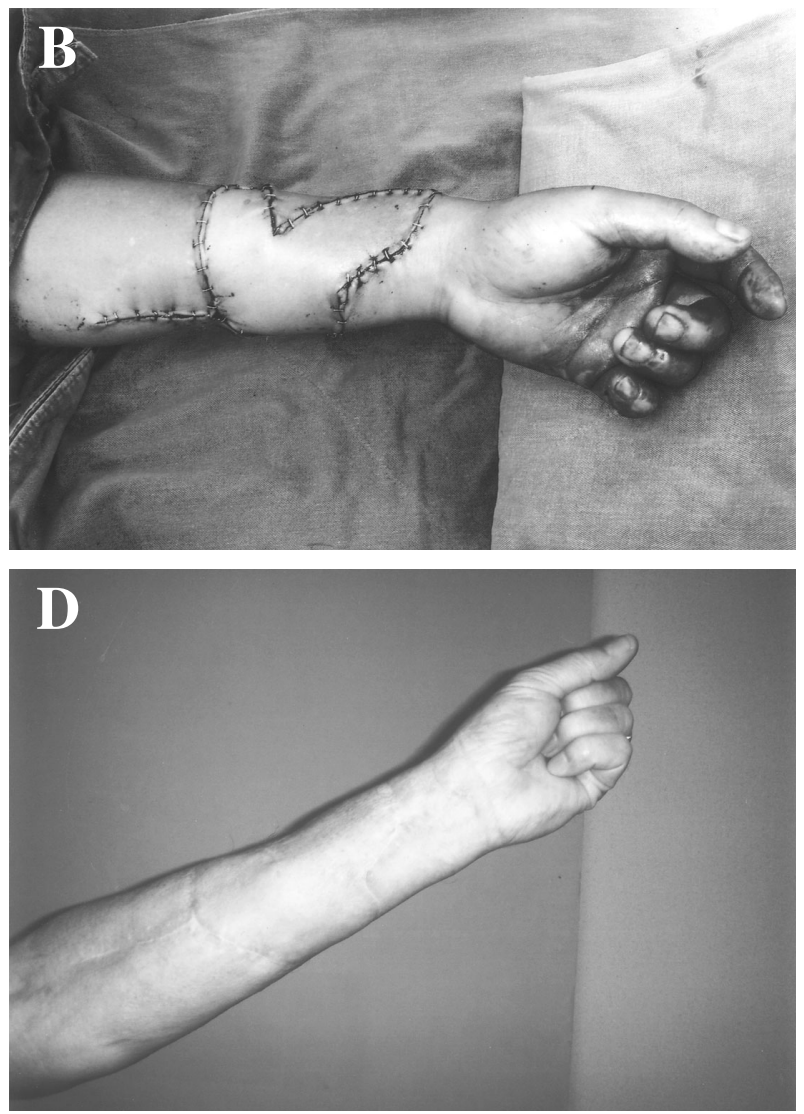

Fig. 5 (A) Bilobed design of a radial forearm flap. (B) Closure with adjacent skin paddle based on ulnar perforators. (C) Hand in extension. (D) Hand in flexion.

artery and its accompanying venae comitantes. This descending branch travels between the rectus femoris and vastus lateralis muscles, sending perforators to the skin either via the septum of the two muscles or through the vastus lateralis. The perforators that travel in the septum are commonly known as septocutaneous perforators while those that pass through the vastus lateralis are known as musculocutaneous perforators. The musculocutaneous perforators are responsible for the blood supply of the skin in $86 \%$ of cases while the remaining $14 \%$ depend on the septocutaneous perforators. ${ }^{(37-39)}$

The ALT flap for free tissue transfer is popular among microsurgeons is because of its tissue versatility ${ }^{(37,39)}$ long pedicle length and sizable vessels for microanastomosis, excellent location and good donor site outcomes. More than $80 \%$ of donor sites of the anterolateral thigh flap can be closed primarily. Furthermore, the donor site wound can easily be hid- den under clothing, so the aesthetic outcome is excellent. Nevertheless, a percentage of patients still suffer donor site morbidities, mainly resulting from skin grafting. As the harvest and clinical application of the ALT have been well established in the new millennium, there has been a shift in attention to improve donor site morbidity. ${ }^{(40,41)}$

Achieving primary closure at the ALT flap donor site is the key factor in a satisfactory aesthetic outcome. In order for surgeons to better plan a flap design to ensure sufficient tissue for reconstructing the defect and yet avoid skin grafting at the donor site, a reliable parameter to predict the possibility of primary wound closure is needed. Most published data suggest that the width of the ALT flap should range from 6 to $10 \mathrm{~cm}$ to allow primary wound closure. ${ }^{(42-44)}$ However, these approaches are not reliable, as they do not take individual variability and the overall circumference of the donor thigh into consid- 
eration. Instead, we used the flap width-to-thigh circumference ratio rather than the absolute measurement. ${ }^{(45)}$ We concluded that primary closure of an ALT donor site could be achieved if the flap widthto-thigh circumference ratio was less than 16 percent (Fig. 6). If the flap width equals or exceeds 16 percent of the thigh circumference, the donor site can be closed by skin grafting. However, this results in a significantly higher rate of muscle herniation. ${ }^{(45)}$ Alternatively, in order to improve the aesthetic outcome by not having any skin graft, large ALT donor sites can be closed by either employing a tissue expander, ${ }^{(46)}$ or using the remainder island flap from the distal portion of the ALT (which is based on a separate perforator) to close in a V-Y advancement
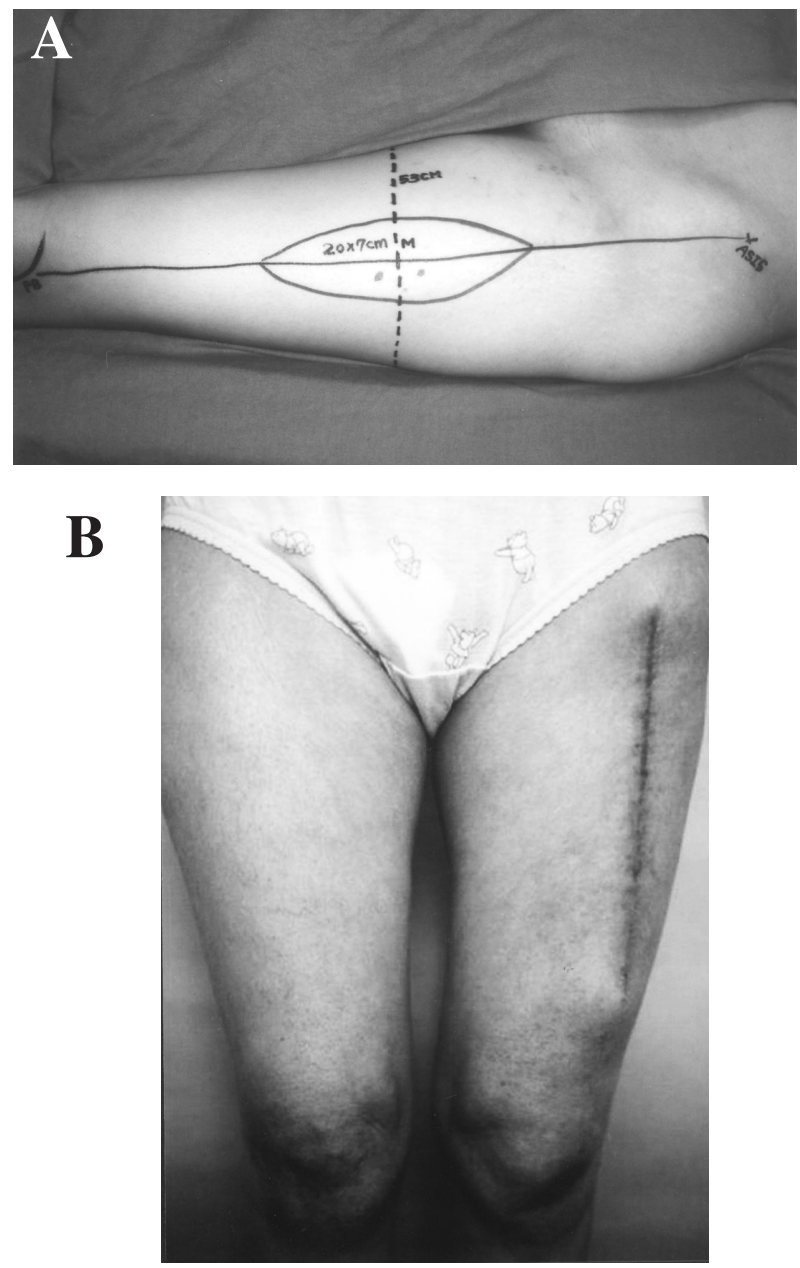

Fig. 6 (A) The width of an anterolateral thigh flap is less than $16 \%$ of the total circumference of the thigh. (B) Primary closure of the anterolateral thigh flap. fashion. $^{(47)}$

With a reliable parameter to predict primary closure of a donor site, surgeons can accurately design a flap that provides ample tissue for reconstruction and at the same time maintain a good aesthetic outcome for the donor site.

\section{Improving harvesting techniques}

Most morbidity of donor sites can be avoided with proper design and harvest. There are many different techniques for harvesting a flap. Traditional open methods are still commonly used. Undoubtedly, this allows good exposure and safe surgery. Open techniques, however, frequently leave a long and undesirable donor site scar. Much effort has been made in finding strategies that require a minimal donor site wound but still allow surgery to proceed safely. Minimally invasive surgery is one such strategy. Minimally invasive surgical methods for harvesting flaps can decrease donor site scars and postoperative morbidity, and improve aesthetic outcomes. Most minimally invasive surgery utilizes endoscopic equipment and techniques to assist in flap harvest. Although endoscopic techniques can greatly improve aesthetic outcomes, they often result in higher costs, as special equipment is needed. Moreover, a steep learning curve is usually needed in training in endoscopic surgery. ${ }^{(48,49)}$ Minimally invasive surgical techniques are not limited to endoscopy. We will present our technique for harvesting the gracilis muscle flap in a minimally invasive manner without the use of endoscopic equipment. ${ }^{(50)}$

An easy modification in harvesting techniques can sometimes greatly improve donor site outcomes. This is well illustrated by Lutz et al, who introduced the suprafascial method of harvesting a radial forearm flap. ${ }^{(34)}$ Leaving the fascia behind during flap dissection can increase the success of skin grafting on the donor site, as the skin graft does not come into direct contact with any bare tendons. This invariably improves the donor site outcome. This modification, although simple, is effective and may also be utilized during harvest of other flaps that require skin grafting to close the donor site. An illustration of this with the free fibula osteocutaneous flap will be described below.

\section{Gracilis flap}

Harii et al introduced this free flap in 1976 and 
it was one of the first musculocutaneous flaps to be transferred by microvascular techniques. ${ }^{(51)}$ Subsequently, it has been primarily used in the head and neck region as a muscular flap for dynamic facial reanimation, as the muscle can be both revascularised and reinnervated.

The gracilis muscle is a long thin muscle, 4 to 6 $\mathrm{cm}$ wide, originating from the pubic tubercle. The terminal branch of the adductor artery supplies this muscle. It arises from the profunda femoris or from the medial femoral circumflex artery and runs between the adductor longus anteriorly and the adductor brevis and magnus posteriorly before entering the gracilis at the junction of the upper and lower two thirds of muscle. The point where the vessel enters the muscle is consistently located 5 to $10 \mathrm{~cm}$ below the pubic tubercle. ${ }^{(48)}$ Conventionally, the gracilis muscle flap is harvested by an open method. This requires a skin incision about $17 \mathrm{~cm}$ long, ${ }^{(48)}$ depending on the patient's habitus and the length of gracilis needed. This long incision may result in wound healing problems or unsightly scars. ${ }^{(52-56)}$ Endoscopic-assisted harvest became popular in the early 1990s. This technique decreases scarring, lowers post-operative complications and allows early ambulation of patients. ${ }^{(57-59)}$ Donor site morbidity has been greatly improved with the advent of this new technique. However, as with all endoscopic operations, muscle harvest using this method entails the use of specialized instruments, resulting in a rise in costs.

A minimally invasive alternative for harvesting the gracilis muscle can be carried out without endoscopic assistance. ${ }^{(48,60)}$ This is done via a short $5 \mathrm{~cm}$

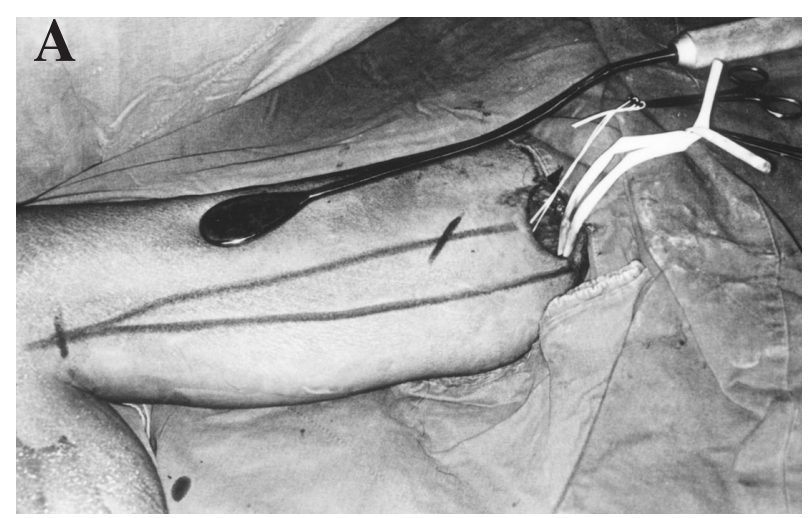

upper thigh incision and a $1.5 \mathrm{~cm}$ transverse incision at the area of the gracilis tendon insertion around the knee. A standard long blunt dissector used for augmentation mammoplasty is utilized to assist in the dissection of the full length of the gracilis muscle. The average harvest time for this technique is less than with the conventional technique. Further, instead of using a longitudinal upper thigh skin incision, we refined this technique with a transverse groin crease incision to further enhance the aesthetic results of the donor site scar (Fig. 7). ${ }^{(60)}$ The main advantage of our minimally invasive technique is that it achieves the results of endoscopic- assisted surgery without the need for special instruments and training. This is an important illustration of how improving harvesting techniques can bring about a major breakthrough in enhancing the aesthetic outcomes of donor sites.

\section{Fibular osteocutaneous flap}

Taylor et al first reported the successful transfer of a vascularised fibular bone flap in 1975. ${ }^{(61)}$ Chen and Yan first reported the transfer of a fibular osteocutaneous flap in $1983 .{ }^{(62)}$ Wei et al then designed a proximal skin paddle combined with a distal bone segment to separate and increase the flexibility of the two components of this composite flap. ${ }^{(63)}$ Eventually, this osteocutaneous flap was not only useful for reconstructing long bone defects, but became the workhorse for reconstructing mandibular defects in head and neck surgery.

The fibular osteocutaneous flap derives its primary blood supply from the peroneal artery and vein. The peroneal artery and its two venae comitantes

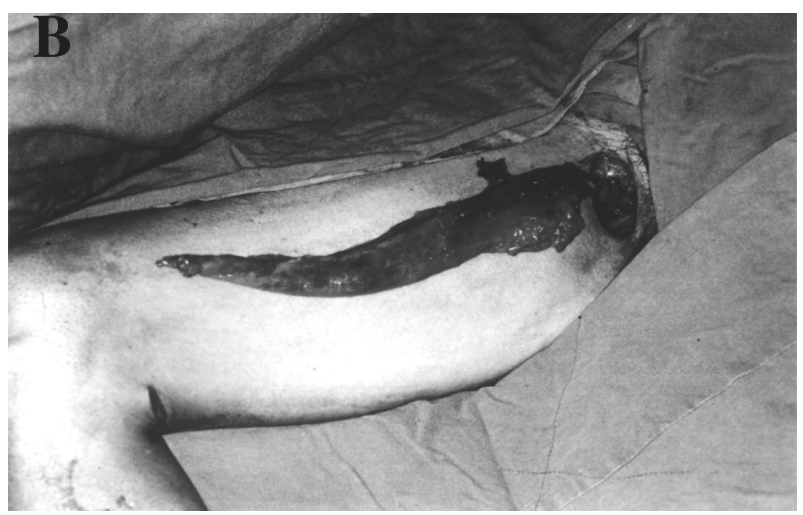

Fig. 7 (A) Minimally invasive harvest design of a gracilis flap. (B) The donor site wound could be concealed under the clothes easily. 
descend into the lower leg between the flexor hallucis longus and the tibialis posterior. In addition to supplying the nutrient artery of the fibula and musculoperiosteal vessels, the peroneal vessels also give rise to fasciocutaneous perforators that run in the posteior crural septum to supply the skin. This is the basis for including a skin paddle in this flap. However, there has been considerable interest in the reliability of the skin paddle. Hidalgo et al only had a $20 \%$ success rate with the skin paddle surviving in its entirety. ${ }^{(64)}$ Wei et al on the other hand reported a $100 \%$ success rate with the skin paddle of this flap in 80 cases of extremity reconstruction and 27 cases of mandibular reconstruction. ${ }^{(63)}$ The authors reported that the posterior crural septum had to be included with the flap and that excess traction during harvest or closure was detrimental to the blood supply of the skin paddle. We also found the skin paddle to be very dependable.

Although the donor site of the free fibula flap results in little morbidity, complications and complaints about the donor site must not be ignored. Skin defects up to $4 \mathrm{~cm}$ wide at the donor site can usually be closed directly to achieve the best cosmesis. ${ }^{(65)}$ Nonetheless, skin grafting for closure is more common and can result in cold intolerance, pain and weakness, decreased range of movement and a poor esthetic outcome. Some of these complaints can be attributed to the classic method of subfascial elevation of the skin paddle, resulting in split skin grafting directly on muscles and tendons during closure. This can result in poor aesthetics of the donor site, and adhesions can form and subsequently decrease the gliding effect that is provided by the fascia of the muscles. To improve these problems, a refinement in fibula design and harvest technique was made using a suprafascial method of dissection during flap elevation and was compared with a subfascial method of flap elevation. ${ }^{(66)}$ This novel method of harvest allowed most of the muscle fascia to be preserved. Although the functional status between the suprafascial dissection and subfascial dissection groups of patients was not significantly different, quantitative analysis revealed better strength and range of movement in the ankle in patients with suprafascial dissection. Furthermore, preserving the fascia allows superior contour and aesthetic outcomes after skin grafting (Fig. 8).
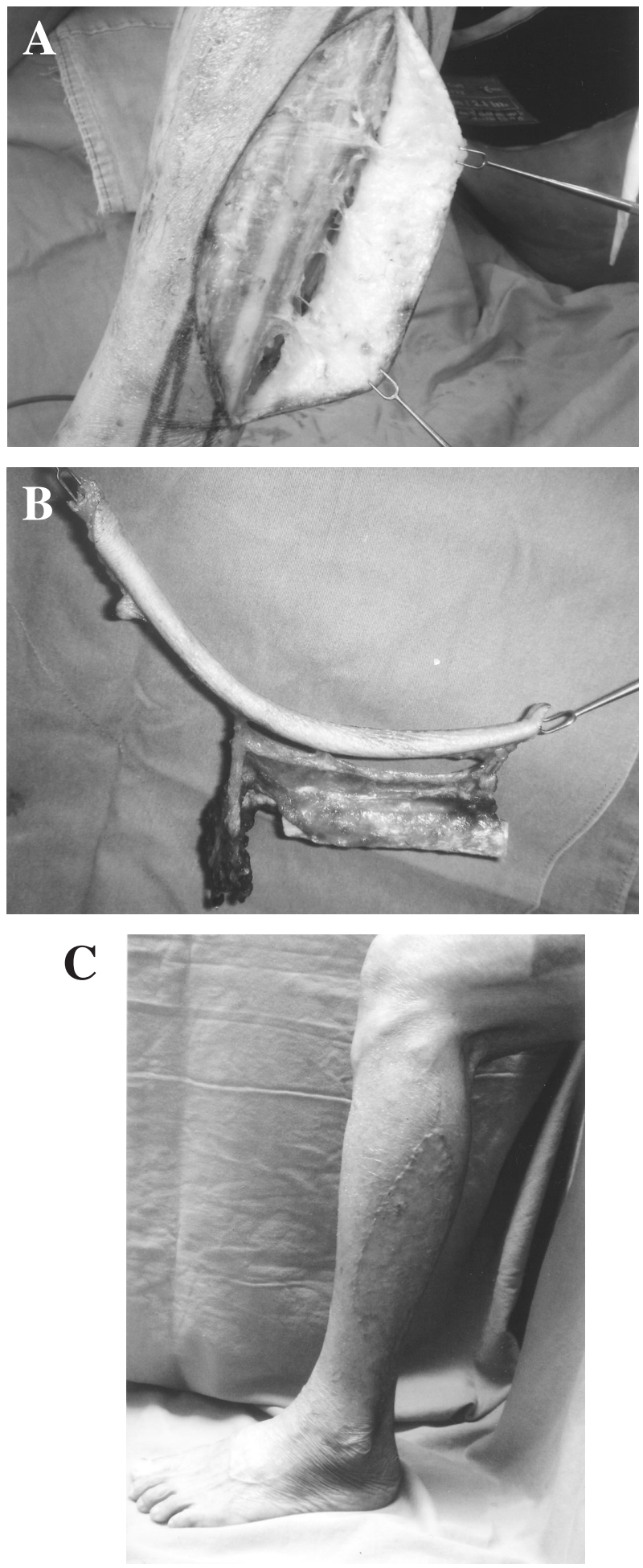

Fig. 8 (A) Suprafascial dissection of a fibula flap. (B) Fibula osteocutaneous flap. (C) Healed donor site wound with skin grafting 6 months after surgery. 


\section{Conclusion}

One of the concerns of modern reconstructive surgery is donor site morbidity and adequate cosmesis. Although this is not easy, it can be done through a variety of strategies as described. Through this article, we hope to (1) increase awareness of donor site morbidity, (2) suggest methods that will improve the donor site outcome in commonly used flaps and perhaps utilize such flaps more frequently, and (3) provide strategies to improve donor site outcomes for other flaps in the future. As newer technologies are devoloped, more should be done to ensure that donor site outcomes continue to improve.

\section{REFERENCES}

1. Brenner MJ, Perro CA. Recontouring, resurfacing, and scar revision in skin cancer reconstruction. Facial Plast Surg Clin North Am 2009;17:469-87.

2. Lin TS, Jeng SF. Full-thickness skin graft as a one-stage debulking procedure after free flap reconstruction for the lower leg. Plast Reconstr Surg 2006;118:408-12.

3. Rudkin GH, Carlsen BT, Miller TA. Nasolabial flap reconstruction of large defects of the lower lip. Plast Reconstr Surg 2003;2:810-7.

4. Hynes B, Boyd JB. The nasolabial flap: Axial or random? Arch Otolaryngol Head Neck Surg 1988;114:1389-91.

5. Martin D, Pascal JF, Baudet J, Mondie JM, Farhat JB, Athoum A, Le Gaillard P, Peri G. The submental island flap: a new donor site. Anatomy and clinical applications as a free or pedicled flap. Plast Reconstr Surg 1993;92: 867-73.

6. Faltaous AA, Yetman RJ. The submental artery flap: an anatomic study. Plast Reconstr Surg 1996;97:56-60.

7. Abouchadi A, Capon-Degardin N, Patenotre P, MartinotDuquennoy V, Pellerin P. The submental flap in facial reconstruction: advantages and limitations. J Oral Maxillofac Surg 2007;65:863-9.

8. Taghinia AH, Movassaghi K, Wang AX, Pribaz JJ. Reconstruction of the upper aerodigestive tract with the submental artery flap. Plast Reconstr Surg 2009;123:56270.

9. Brown WJ. Extraordinary case of horse bite: the external ear completely bitten off and successfully replaced. Lancet 1898;1:1533.

10. Monks GH. The restoration of a lower lid by a new method. N Engl J Med 1898;139:385.

11. Cheney ML, Megerian CA, Brown MT, McKenna MJ, Nadol JB. The use of the temporoparietal fascial flap in temporal bone reconstruction. Am J Otol 1996;17:137-42.

12. Hallock GG. The extended temporoparietal fascia "non free" flap. Ann Plast Surg 1989;22:65-8.

13. Hing DN, Buncke HJ, Alpert BS. Use of temporoparietal free fascial flap in the upper extremity. Plast Reconstr Surg 1988;81:534-44.

14. Rose EH, Norris MS. The versatile temporoparietal fascial flap: adaptability to a variety of composite defects. Plast Reconstr Surg 1990;85:224-32.

15. McCarthy JG, Zido BM. The spectrum of calvarial bone grafting: introduction of the vascularized calvarial bone graft. Plast Reconstr Surg 1984;74:10-8.

16. Boudard P, Benassayag C, Chavez Alvarez F, Portmann D, Bebear JP, Portmann M. Use of a temporoparietal fascial flap in difficult reconstructions of the external ear. Rev Laryngol Otol Rhinol (Bord) 1989;110:219-22.

17. Cheney ML, Varvares MA, Nadol JB Jr. The temporoparietal fascial flap in head and neck reconstruction. Arch Otolaryngol Head Neck Surg 1993;119:618-23.

18. McGregor IA, Jackson IT. The groin flap. Br J Plast Surg 1972;25:3-16.

19. Daniel RK, Taylor GI. Distant transfer of an island flap by microvascular anastomoses. A clinical technique. Plast Reconstr Surg 1973;52:111-7.

20. Harii K, Ohmori K. Free groin flaps in children. Plast Reconstr Surg 1975;55:588-92.

21. Aydin MA, Nasir S. Free SCIA/SIEA skin flap: a dual blood supply approach to groin region. Microsurgery 2007;27:617-22.

22. Chuang DC, Jeng SF, Chen HT, Chen HC, Wei FC. Experience of 73 free groin flaps. Br J Plast Surg 1992;45:81-5.

23. Jeng SF, Wei FC, Noordhoff MC. The composite groin fascial free flap. Ann Plast Surg 1995;35:595-600.

24. Taylor GI, Ham FJ. The free vascularised nerve graft. A further experimental and clinical application of microvascular techniques. Plast Reconstr Surg 1976;57:413.

25. Yang G, Chen B, Gao Y. Forearm free skin flap transplantation. Natl Med J China 1981;61:139.

26. Soutar D. Radial forearm flaps. In: Baker S, ed. Microsurgical Reconstruction of the Head and Ncek. New York: Churchill Livingstone, 1989:139.

27. Reid CD, Moss LH. One stage repair with vascularised tendon grafts in a dorsal hand injury using the "Chinese" forearm flap. Br J Plast Surg 1983;36:473-9.

28. Sanger J, Ye Z, Yousif N, Matloub H. The brachioradialis forearm flap: anatomy and clinical application. Plast Reconstr Surg 1998;101:72-84.

29. Heden P, Gylbert L. Anomaly of the radial artery encountered during elevation of the radial forearm flap. J Reconstr Microsurg 1990;6:139-41.

30. Hsieh CH, Kuo YR, Yao SF, Liang CC, Jeng SF. Primary closure of radial forearm flap donor defects with a bilobed flap based on the fasciocutaneous perforator of the ulnar artery. Plast Reconstr Surg 2004;113:1355-60.

31. Fenton O, Roberts J. Improving the donor site of the radial forearm flap. Br J Plast Surg 1985;38:504-5.

32. McGregor AD. The free radial forearm flap: the management of the secondary defect. Br J Plast Surg 1987;40:83- 
5.

33. Masser M. The pre-expanded radial free flap. Plast Reconstr Surg 1990;86:295-301.

34. Lutz BS, Wei FC, Chang SCN, Yang KH, Chen IH. Donor site morbidity after suprafascial elevation of the radial forearm flap: A prospective study in 95 consecutive cases. Plast Reconstr Surg 1999;103:132-7.

35. Elliot D, Bardsley AF, Batchelor AG, Soutar DS. Direct closure of the radial forearm flap donor defect. Br J Plast Surg 1988;41:358-60.

36. Song YG, Chen GZ, Song YL. The free thigh flap: A new free flap concept based on the septocutaneous artery. Br J Plast Surg 1984;37:149-59.

37. Kuo YR, Seng-Feng J, Kuo FM, Liu YT, Lai PW. Versatility of the free anterolateral thigh flap for reconstruction of soft-tissue defects: review of 140 cases. Ann Plast Surg 2002;48:161-6.

38. Chen HC, Tang YB. Anterolateral thigh flap: An ideal soft tissue flap. Clin Plast Surg 2003;30:383-401.

39. Demirkan F, Chen HC, Wei FC, Chen HH, Jung SG, Hau SP, Liao CT. The versatile anterolateral thigh flap: A musculocutaneous flap in disguise in head and neck reconstruction. Br J Plast Surg 2000;53:30-6.

40. Kimata Y, Uchiyama K, Ebihara S, Sakurata M, Iida H, Nakatsuka T, Harii K. Anterolateral thigh flap donor-site complications and morbidity. Plast Reconstr Surg 2000;106:584-9.

41. Calderon W, Borel C, Roco H, Pineros GL, Olguin F. Primary closure of donor site in anterolateral cutaneous thigh free flap. Plast Reconstr Surg 2006;117:2528-9.

42. Lipa JE, Novak GB, Binhammer PA. Patient-reported donor-site morbidity following anterolateral thigh flaps. J Reconstr Microsurg 2005;21:365-70.

43. Wei FC, Jain V, Celik N, Chen HC, Chuang DC, Lin CH. Have we found an ideal soft-tissue flap? An experience with 672 anterolateral thigh flaps. Plast Reconstr Surg 2002;109:2219-26.

44. Kimata T, Uchiyama K, Ebihara S, Yoshizumi T, Asai M, Saikawa M, Hayashi R, Jitsuiki Y, Majima K, Ohyama W, Haneda T, Nakatsuka T, Harii K. Versatility of the free anterolateral thigh flap for reconstruction of head and neck defects. Arch Otolaryngol Head Neck Surg 1997;123:1325-31.

45. Boca R, Kuo YR, Hsieh CH, Huang EY, Jeng SF. A reliable parameter for primary closure of the free anterolateral thigh flap donor site. Plast Reconstr Surg 2010;126: 1558-62.

46. Hallock GG. The pre-expanded anterolateral thigh free flap. Ann Plast Surg 2004;53:170-3.

47. Yamada N, Kakibuchi M, Kitayoshi H, Matsuda K, Yano K, Hosokawa K. A new way of elevating the anterolateral thigh flap. Plast Reconstr Surg 2001;108:1677-82.

48. Eaves FF, Price CI, Bostwick J. Endoscopically-assisted plastic surgery using a retractor mounted endoscopoc sys- tem. Perspect Plast Surg 1993;7:1.

49. Doi K, Hattori Y, Soo-Heong T, Hiura Y, Kawakami F. Endoscopic harvesting of the gracilis muscle for reinnervated free muscle transfer. Plast Reconstr Surg 1997;100: 1817-23.

50. Jeng SF, Kuo YR, Wei FC. Minimally invasive harvest of the gracilis muscle without endoscopic assistance. Plast Reconstr Surg 2001;108:2061-5.

51. Harii K, Ohmori K, Torii S. Free gracilis muscle transplantation with microvascular anastomosis for the treatment of facial paralysis. Plast Reconstr Surg 1976;56:1335.

52. Yousif N, Matloub H, Kabachalam R, Grunert B, Sanger J. The transverse gracilis musculocutaneous flap. Ann Plast Surg 1992;29:482-90.

53. Carr MM, Manktelow RT, Zuker RM. Gracilis donor site morbidity. Microsurgery 1995;16:598-600.

54. Deutinger M, Kuzbari R, Paternostro-Sluga T, Quittan M, Zauner-Dunyl A, Worseg A, Podoroff B, Holle J. Donor site morbidity of the gracilis flap. Plast Reconstr Surg 1995;95:1240-4.

55. Hallock GG. Minimally invasive harvest of the gracilis muscle. Plast Reconstr Surg 1999;104:801-5.

56. Lin CH, Wei FC, Lin YT. Conventional versus endoscopic free gracilis muscle harvest. Plast Reconstr Surg 2000;105:89-93.

57. Fine NA, Orgill DP, Pribaz JJ. Early clinical experience in endoscopic-assisted muscle flap harvest. Ann Plast Surg 1994:33:465-9.

58. Miller MJ, Robb GL. Endoscopic technique for free flaps harvesting. Clin Plast Surg 1995;22:755-73.

59. Friedlander L, Sundin J. Minimally invasive harvesting of the latissimus dorsi. Plast Reconstr Surg 1994;94:881-4.

60. Lin PY, Kuo YR, Kueh NS, Jeng SF. Refinement of minimally invasive harvest of gacilis muscle flap without endoscopic assistance. J Reconstr Microsurg 2003;19: 537-41.

61. Taylor GI, Miller GD, Ham FJ. The free vascularised bone graft: a clinical extension of microvascular techniques. Plast Reconstr Surg 1975;55:533-44.

62. Chen Z, Yan W. The study and clinical application of the osteocutaneous flap of fibula. Microsurgery 1983;4:11-6.

63. Wei FC, Seah C, Tsai Y, Liu S, Tsai M. Fibula osteoseptocutaneous flap for reconstruction of composite mandibular defects. Plast Reconstr Surg 1994;93:294-304.

64. Hidalgo D. Fibula free flap: new method of mandible reconstruction. Plast Reconstr Surg 1989;84:71-9.

65. Wei FC, Chen HC, Chuang CC, Noordhoff MS. Fibular osteoseptocutaneous flap: anatomic and clinical application. Plast Reconstr Surg 1986;78:191-200.

66. Qualitative and quantitative analyses of donor-site morbidity following suprafascial versus subfascial free fibula flap harvesting. Plast Reconstr Surg 2011;128:137-45. 


\title{
使供皮區外觀上及功能上的結果最佳化 \\ 鄭勝峰 Ngian Chye Tan ${ }^{1}$
}

\begin{abstract}
近年, 因顯微重建手術的成功率在大多數的醫學中心已接近百分之九十五, 爲了更求完 美, 近代的整形重建醫師會把注意力由 “受與區” 轉移到 “供給區”。成功的重建必須顧及到 雨處的合併症降到最低。本篇論文目的在使讀者可以重新温習以往對 “供給區”的處置, 進 而使用創新的外科技術來隱藏供給區並美化傷口, 以期符合現代病患對身體缺損後的整形重 建, 在功能性和美觀性的要求。(長庚醫誌 2012;35:219-30)
\end{abstract}

關鍵詞：重建手術, 美觀結果, 功能結果, 併發症, 供皮區

義大醫院 整形外科 ; 1長庚醫療財團法人高雄長庚紀念醫院 整形外科

受文日期：民國99年11月4日；接受刊載：民國100年12月7日

通訊作者: 鄭勝峰教授, 義大醫院 整形外科。高雄市824燕巢區義大路1號。Tel: (07)6150011轉2977; Fax: (07)6155352;

E-mail: jengfamily@hotmail.com 